\title{
Preparation and Bending Properties of Lattice Sandwich Structure for Wooden Truss
}

\author{
Xue WANG ${ }^{1, \mathrm{a}}$ and Ying-Cheng $\mathrm{HU}^{1, \mathrm{~b},{ }^{*}}$ \\ ${ }^{1}$ Key Laboratory of Bio-based Material Science and Technology of Ministry of Education of China, \\ College of Material Science and Engineering, Northeast Forestry University, \\ Harbin 150040, China \\ awangxue1@vip.sina.com byingchenghu@nefu.edu.cn \\ * Corresponding author
}

Keywords: Lattice Sandwich Structure of Wooden Truss; Bending Performance; Lattice Sandwich Structure of Synclastic Truss; Lattice Sandwich Structure of Incongruous Truss.

\begin{abstract}
Based on an internally interlinked concept of space design, poplar LVL and oriented strand board (OSB) as panel respectively and mongolica sawn timber as truss member, gluing approach is adopted to combine truss members into single truss for core structure in this paper. There are four categories of prepared lattice sandwich structure of wooden truss, including lattice sandwich structure of poplar veneer synclastic truss, lattice sandwich structure of poplar veneer incongruous truss, lattice sandwich structure of OSB veneer synclastic truss and lattice sandwich structure of OSB veneer incongruous truss; nodes of prepared lattice sandwich structure for wooden truss are reinforced with bidirectional carbon cloth. The loading method of three-point bending should be adopted to test the bending properties of these four wood-based truss lattice sandwich structure and compare and analyze the rationality of material selection and structural design for the purpose for selecting the lattice sandwich structure for wood-based truss with optimal bending performance. The experimental results show that: Lattice sandwich structure for poplar veneer truss is superior to that for OSB truss in bending performance; lattice sandwich structure for incongruous truss with the same panel material overmatches that for synclastic truss in bending performance.
\end{abstract}

\section{Introduction}

In recent years, shortage of wood resources and the requirements of fire and corrosion prevention for timber have caused people to pay more attention to the study of sandwich structure. Sandwich structure is similar to the unit cell structure, its core is equivalent to connections between the atoms in the unit cell, and the panel is approximate to the plane formed by the atomic configuration. Therefore the sandwich structure is featured with high strength-to-weight and large void ratio, and studies show it also has strong breaking tenacity[1]. What's more, with a full use of mechanical property, sandwich structure is of materials-saving and high cost performance. By virtue of its thin panel, light but large rigidity compared with solid structure, the sandwich structure has excellent effect on weight loss, which is a structural material with high efficiency[2]. Compared with traditional wood-based slab, void of sandwich structure could be embedded with a variety of tiny components, which allows the structure to be of sound and thermal insulation. In the 21st century, Professor Hutchinson of Harvard University and Professor Evans of Princeton University, et al put forward the concept of three-dimensional lattice sandwich structure [3-4], that is, the sandwich structure is specifically composed by pony-size connections and member units after combining existing space truss with sandwich structure[5]. This structure has the characteristics of easy connectivity, high strength-to-weight, and its large void ratio provides a guarantee for the embedment of various functional materials, which allow it to become an important multi-functional material structure.

Some studies about sandwich structure pre-pared by carbon fiber composite have been found, mainly involving in prepreg hot-press and insertion \& gluing approaches. FAN Hualin made studies of changes in bending strength of lattice materials re-lated to thickness of panel[6] in 2013. In 2014 
after-wards, Wang B and Zhang G prepared 2D carbon fiber reinforced composite sandwich structure [7]. Wooden sandwich structure usually is composed of upper and lower panels and intermediate light sand-wich structure [8]. In 2009, LIU Weiqing et al[9] pre-pared a sandwich structure material, composed of glass fiber resin panels and paulownia wood core material, for the rapid assembly of pavement surface; in 2012, LIU Weiqing[10] and others further studied the bending properties of sandwich beam specimens with paulownia wood as core material, glass fiber reinforced plastic and bamboo as surface layer. Tamami Kawasak and Shuichi Kawai prepared a sandwich panel, composed of wooden laminate panel and core of low-density fiber board, for the wood-based structure, and studied its in-plane shear properties[11], thermal conductivity and insulation properties[12], as well as the effects of different panel materials, panel thickness and core density on the mechanical properties[13]. These experiments show that this kind of wooden sandwich panel has excellent thermal insulation properties while maintaining a suitable thickness, and also has light weight compared to common building wall materials[14]. Characteristics of easy to make and enough thickness allow this kind of sandwich plate to be widely used in buildings whose insulation performance is highly required. In 2010, Atas et al.[15] studied the behavior of balsa core and PVC foam core (epoxy resin-based glass fiber composites as panels) under impact loading; Furthermore, in 2011, Chen et al.[16] studied the bending creep properties of sandwich structural plates commonly used in furniture and made from plywood, medium-density fiberboard or cardboard for panels and kraft paper honeycombs as cores; C.O' Loinsigh et.al[17-18] studied the connection of wood beams by means of the insertion of dowels, demonstrating the validity of the mechanical behav-ior of the mechanical properties of the wooden pin combination in a wooden sandwich structure. The above-mentioned wood-based panels have certain advantages in its application areas, and some have been widely used in the actual production and living. Although these wooden sandwich structures effec-tively enhance their mechanical properties, it is still difficult to achieve their own needs to cope with multi-functional needs of improvement. With respect to current market environment in China, the low-grade timber, such as fast-growing wood in Southern China, has occupied an increasing proportion of wood materials; globally, such timber has been developed deeply and utilized rapidly. Currently, scrimber and LVL are the main wood-based composite material products on the wood material market. As the wood material, it can be deemed that they have overcome the disadvantages of the wood such as anisotropy, making it possible for the high-efficiency utilization of natural materials which have been difficult to be used in the past. But they have low strength and stiffness, high weight, high price and difficulties in the integration with the functions such as flame retardant, thermal insulation and sound absorption. These disadvantages still put limits on their usage in specific fields, such as the field where function expansion is needed or high strength is required. Therefore, for a long time, how to improve the usage structure of wood material to realize the purposes of saving quality wood and making good use of bad wood, has always been a main research direction of relevant research fields.

In the research field of carbon fiber materials, the preparation technology of carbon fiber lattice sandwich structure has already been perfect, in which the pre-prepared material formation method and mortise and tenon jointing method have been widely used. Currently, the sandwich structure materials made from carbon fiber or metal materials are mainly used in the aerospace engineering field. But for the wood structure, there is no report on preparing truss lattice sandwich structure with wood composite materials.

\section{Experiment Materials and Method}

\section{Experiment Materials}

The Oriented Strand Board (OSB) to be used is purchased from the Hubei Baoyuan Wood Industry Co., Ltd. The finish size is $850 \mathrm{~mm} \times 60 \mathrm{~mm} \times 15 \mathrm{~mm}$ and it's used as the face materials of the wooden truss lattice sandwich structure. Poplar LVL (Lum-ber Veneer Laminate) is purchased from the Shan-dong Shouguang Fushi Wood Co., Ltd. The finish size is $850 \mathrm{~mm} \times 60 \mathrm{~mm} \times 15 \mathrm{~mm}$ and it's used as 
the face materials of the wooden truss lattice sandwich structure. The mongolica sawn timber is purchased from the Hangzhou Jimuwu Model Co., Ltd. There are three different sizes, which are $120 \mathrm{~mm} \times 15 \mathrm{~mm} \times 15 \mathrm{~mm}, 170 \mathrm{~mm} \times 15 \mathrm{~mm} \times 15 \mathrm{~mm}$ and $850 \mathrm{~mm} \times 15 \mathrm{~mm} \times 15 \mathrm{~mm}$. The carbon fiber woven fabric is the $3 \mathrm{k}-200 \mathrm{~g}$ bi-directional woven carbon cloth manufactured by Shanghai Miaohan Architecture Technology Co., Ltd. White emulsion adhesive and polymer isocyanate are manufactured by Harbin Lvshidai Adhesive Industry Co., Ltd. and the type is K-3897.

\section{Preparation Technology}

\section{Sawing the rod pieces}

Use single-chip edger to process the mongolica sawn timber to make rod pieces of $15 \mathrm{~mm} \times 15 \mathrm{~mm} \times 120 \mathrm{~mm}, 15 \mathrm{~mm} \times 15 \mathrm{~mm} \times 170 \mathrm{~mm}$ and $15 \mathrm{~mm} \times 15 \mathrm{~mm} \times 850 \mathrm{~mm}$, which are used as the vertical rod, the diagonal web member and the upper or lower chord of single trusses in the sandwich structure.

\section{Assembling the single truss}

Combine the white emulsion adhesive and pol-ymer isocyanate at 10: 1 , and all the adhesives used hereinafter is all in this proportion. Use hairbrush to put adhesive on both ends of the vertical rods and put them at corresponding locations of upper and lower rods and then fix them with fixture for $5 \mathrm{~min}$. After putting adhesive evenly on faces at both ends of the diagonal web member, lay them between the vertical rods according to the designed arrangement mode. Fix them with fixture for 10 min and the remove the fixture.

\section{Assembling the panel}

Take the poplar veneer incongruous truss lattice sandwich structure as an example, put adhesive on faces at both long ends of the poplar LVL with the amount being $180 \mathrm{~g} / \mathrm{m}^{2}$; And then stick the single truss on both sides to make the upper chord parallel with the exterior surface of the top panel and the lower chord parallel with the exterior panel of the down panel. Use fixture to fix them and apply prop-er pressure for formation. Remove the fixture after half an hour of standing.

\section{Reinforcement of the nodes}

Cut the bi-directional carbon fiber woven fabric into pieces of $60 \mathrm{~mm} \times 60 \mathrm{~mm}$ and stick them at the join nodes. Apply certain pressure and put them in standing for one hour.

Wood truss type lattice sandwich structure should be prepared in the above mentioned aggluti-nation method. It should be noted that the fixture should better be fixed on the nodes and some scale error may exist because of the thickness caused by the adhesive put on the diagonal web members, so you need to apply a little pressure when bonding the rod pieces to make them fully contacted. Prepare four groups of wooden truss lattice sandwich struc-ture model which is shown as Fig. 1.

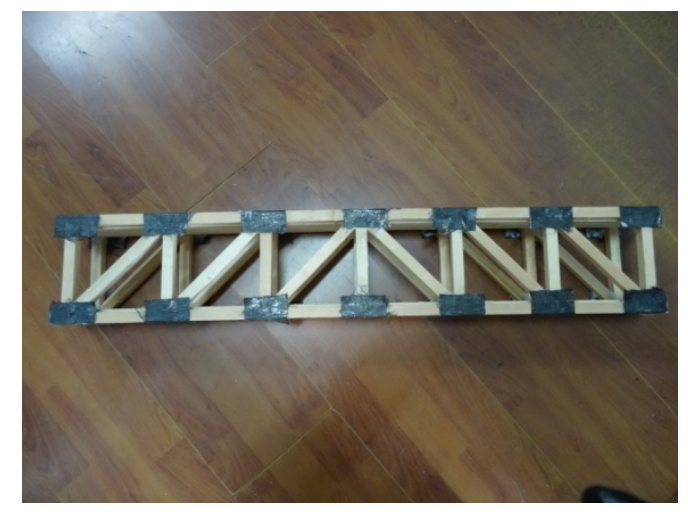

Fig. 1 Lattice Sandwich Structure of Synclastic Poplar LVL Lumber Truss 


\section{Static Bending Test}

In order to discuss the influence of two sides of truss made of different plate materials on the bend-ing performance of wooden truss lattice sandwich structure, we choose single plate and OSB as the plate material and the mongolica sawn timber as the core truss material and we use four kinds of wooden truss sandwich structures in the way of gluing. Use CMT5504 universal testing machine of mechanical laboratory to test wooden truss lattice sandwich structure on the 82 three-point bending performance. The width,height of lattice sandwich structure wooden truss and the distance of two sets is 90,150 and 760mm (shown in Fig.2(a)),respectively. Experiment principle and setting drawing of wooden truss lattice sand-wich structure is shown as Fig. 2(b).

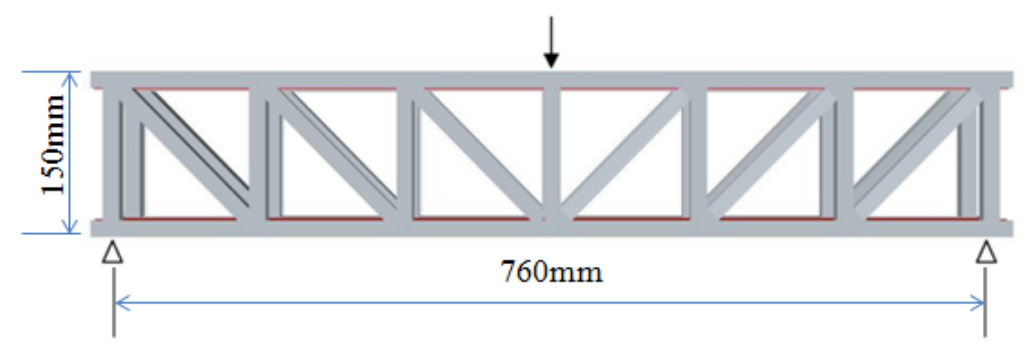

(a)Sketch for three-point bending test

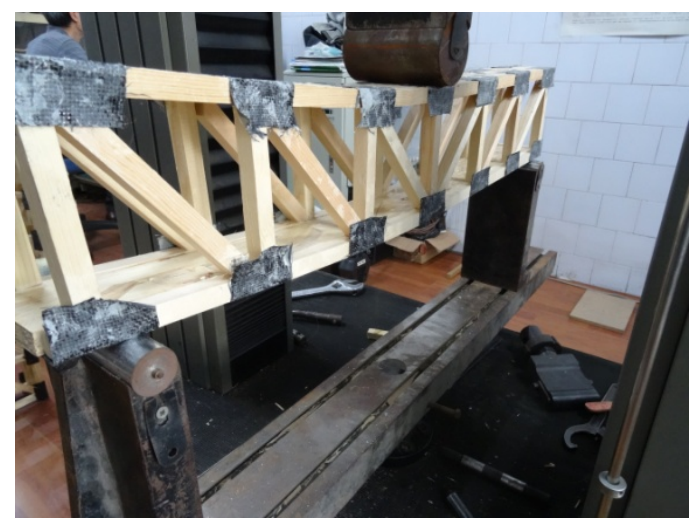

(b)The set for three-point bending test

Fig. 2 Three-point Bending Schematics and Experimental Apparatus of Wooden Truss Lattice Sandwich Structure

\section{Results and Discussion}

\section{Bending Performance of Wooden Truss Lattice Sandwich Structure}

By using four kinds of wooden truss lattice sandwich structures, the three-point bending test says that the max force of the structures can bear is as follows: Incongruous truss lattice sandwich structure of poplar LVL is $8277 \mathrm{~N}$; synclastic truss lattice sandwich structure of poplar LVL is 6441N; incongruous truss lattice sandwich structure of OSB is $4424 \mathrm{~N}$; synclastic truss lattice sandwich structure is $3453 \mathrm{~N}$. The load - replacement curve is shown as Fig. 3. As a whole, we can see the load-replacement curve of the struc-ture have three phases, which are linear elasticity, serrate volatility and the secondary loading summit platform. In the phase of linear elasticity, the curve surges up directly and then go like serrate volatility after the rod separation and slight formation of plate, which is led by the sawn timber of enhanced bend-ing sample is getting off. In the process of separation of rod, it constantly forms a new metastable forcing structure. Loading curve fluctuates like serrates. At the end of serrate volatility, the curve does not go down quickly, but it will show a 
long platform phase, which is because of the main function of bending. Entering in the third phase, the structure force decreases until the thorough breakage of the whole structure.

Compared to samples with different rods which is shown in Fig. 3(a) and (b) and Fig. 3 (c) and (d). We can see that the bending performance of incongruous truss lattice sandwich structure is better. We can also see the bending samples made of differ-ent plate materials. In Fig. 3(b) and Fig. 3(d), its force ladder effect becomes stronger. The fluctuation of serrate becomes severe, which shows the quasi-stable state of incongruous rod in the process of breakage of bending samples becomes unstable, which also shows that the bending samples of incongruous rod relays on stability which can provide strength.
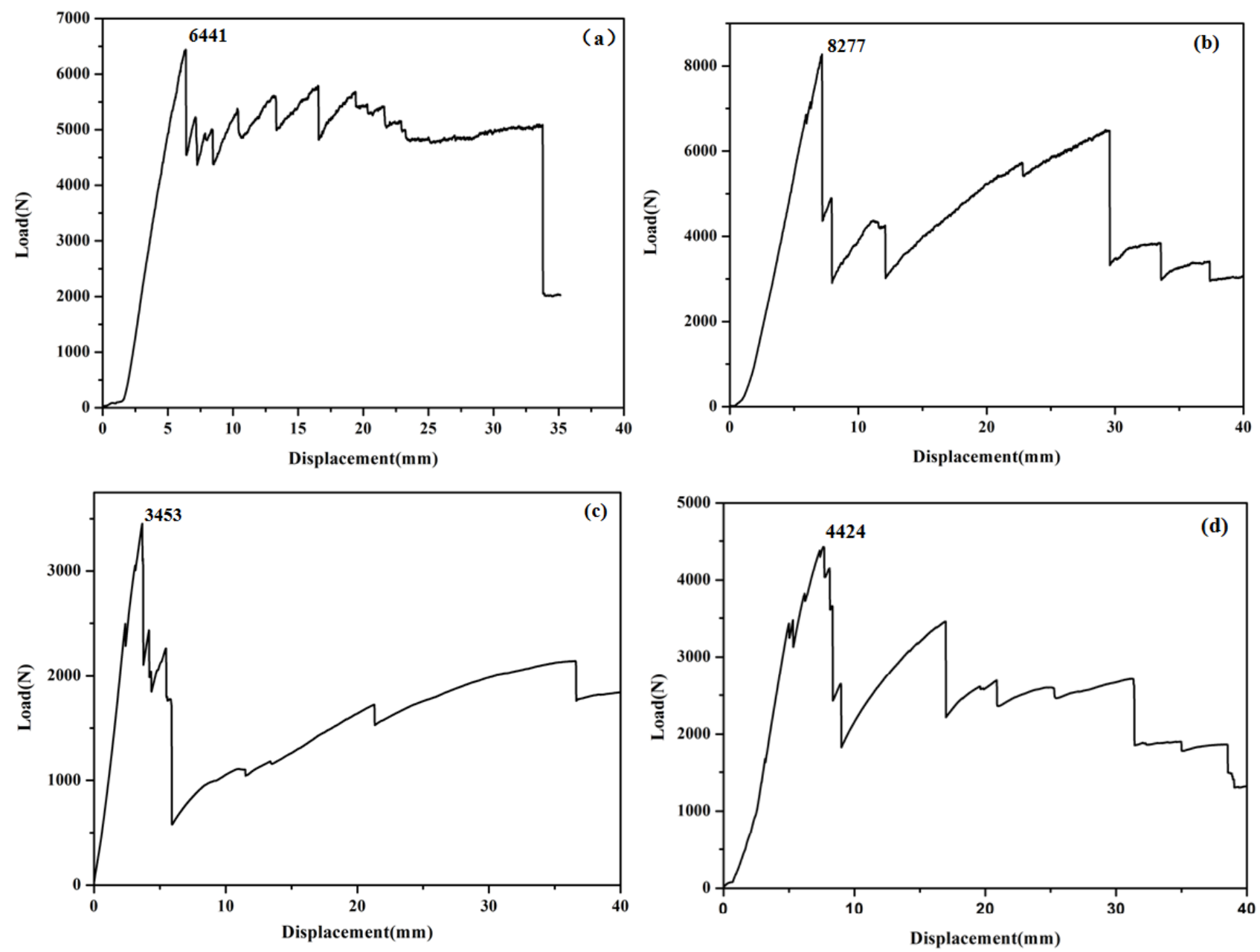

Fig. 3 Three-point bending load and replacement curve. (a) Synclastic poplar single plate with truss lattice sandwich structure; (b) Poplar single plate incongruous truss lattice sandwich structure; (c) OSB synclastic truss lattice sandwich structure (d) OSB incon-gruous truss lattice sandwich structure

The phase of the sample of OSB plate in the serrate changes is shorter than that of LVL. The sawn timber rod is quicker than its getting away. The reason is that OSB mechanical properties is weaker. It is easier to bend, which makes rods get away in a quicker way. It can get into the flexibly bending phase early. The force goes up conversely.

In the test, part of rods of enhanced bending samples can get away before the breakage of plates. The formation of plates is slight, but the sample does not bend down quickly and perform great toughness due to the enhancement function of carbon fiber woven cloth. 


\section{Conclusion}

Wood truss lattice sandwich structures of plates made of different materials have the similar load-replacement curve. Several loading summit values shall be determined by plates' materials. The maxi-mum bending stress of anisotropic poplar LVL shall be greater than that of bending sample of OSB. Each time it reaches the loading summit values, the loading value of bending sample of LVL plate is larger than that of bending sample of OSB plate, which shows that the maximum bending stress of bending sample at the summit shall be determined by the strength of the plate itself.

As for the bending sample of the same plate material, the stress laddering effect of incongruous truss lattice sandwich structure becomes bigger and its serrate volatility becomes severe, which shows that quasi-stable state formed in the breakage of bending sample of incongruous truss becomes more unstable and also shows that bending sample of in-congruous truss lattice sandwich structure relies on the stability of structure which can provide enough strength.

Lattice sandwich structure for poplar LVL is superior to that for OSB truss in bending performance; lattice sandwich structure for incongruous truss with the same panel material overmatches that for synclas-tic truss in bending performance.

\section{Acknowledgements}

This project was supported by the National Natural Science Foundation of China(31470581),the Funda-mental Research Funds for the Central Universi-ties(2572016EBJ1).

\section{References}

[1] XU Chaoyang. Research of the performance of composite sandwich materials made in wood shaped like a honeycomb. PhD dissertation of Nanjing Forestry University 2007.

[2] YAN Minghao. Main materials of modern airplane [J] aircraft material 1980 (4), 1-7

[3] Evans A G, Hutchinson J W, Fleck N A, et al. The topological design of multifunctional cellular metals. Progress in Materials Science, 2001, 46: 309-327.

[4] J.C.Wallah, L.J.Gibson. Mechanical behav-ior of a three-dimensional truss material. International Journal of Solid and Sstructures, 38(2001): 7181-7196.

[5] V.S. Deshpande, N.A. Fleck, M.F. Ashby. Effective properties of the octet-truss lattice materi-al.Journal of the Mechanics and Physics of Solids, 49 (2001) : 1747-1769.

[6] Fan H, Yang L, Sun F, et al. Compression and bending performances of carbon fiber reinforced lattice- core sandwich composites. Composites Part A: Applied Science and Manufacturing, 2013, 52: 118-125.

[7] WU Linzhi, XIONG Jian, MA Li and so on Research development of lattice structure of new composite material [J]. Development of Mechanics 2012, 42 (1): 1-5

[8] Wang B, Zhang G, He Q, et al. Mechanical behavior of carbon fiber reinforced polymer compo-site sandwich panels with 2-D lattice truss cores. Ma-terials \& Design, 2014, 55: 591-596.

[9] FANG Hai, LIU Weiqing, WAN Li. Prepa-ration and mechanical behavior of road mat of composite material made of light paulownia wood. Roadway in China and abroad, 2009, 29 (3): 222-225.

[10] CHEN Lin, LIU Weiqing, FANG Hai. New bamboo-wood- GFRP-sandwich beam's bending per-formance test Journal of Guangxi University (Natural science edition), 2012, 37. (4): 614-622.

[11] Kawasaki T, Hwang K, Komatsu K, et al. In-plane shear properties of the wood-based sandwich panel as a small shear wall evaluated by the shear test method using tie-rods. Journal of wood science, 2003, 49(3): 199-209. 
[12] Kawasaki T, Kawai S. Thermal insulation properties of wood-based sandwich panel for use as structural insulated walls and floors. Journal of wood science, 2006, 52(1): 75-83.

[13] Kawasaki T, Zhang M, Wang Q, et al. Elastic moduli and stiffness optimization in four-point bending of wood-based sandwich panel for use as structural insulated walls and floors. Journal of Wood Science, 2006, 52(4): 302-310.

[14] Atas C, Sevim C. On the impact response of sandwich composites with cores of balsa wood and PVC foam. Composite Structures, 2010, 93(1): 40-48.

[15] Chen Z, Yan N, Deng J, et al. Flexural creep behavior of sandwich panels containing Kraft paper honeycomb core and wood composite skins. Materials Science and Engineering: A, 2011, 528(16): 5621-5626.

[16]C. O’Loinsigh, M. Oudjene, H. Ait-Aider c, et al. Experimental study of timber-to-timber compo-site beam using welded-through wood dowels. Con-struction and Building Materials, 2012; 36: $245-250$.

[17] Cian O'Loinsigh, Marc Oudjene , Elisabeth Shotton , et al. Mechanical behaviour and 3D stress analysis of multi-layered wooden beams made with welded-through wood dowels. Composite Structures, 2012;94: 313-321.

[18] JIN Mingmin. Research of mechanical property of lattice sandwich structure made of wood. Master's Dissertation of Northeast Forestry University 2014 